\title{
The contribution of economic intelligence to the firm performance
}

\author{
Amine Ben Hadj Hassine \\ Department of Management Sciences, Higher Institute of Informatics and Management of Kairouan, Kairouan University, Kairouan, 3100, Tunisia
}

\begin{abstract}
To the extent that the company is an "open system", it must be in a continuous standby state. In this research work, we will try to focus on the contribution of economic intelligence strategies to the performance of the company. We will begin with a literature review to better understand the theoretical concepts. Then we will conduct a field study of 92 Tunisian industrial companies. Our work has revealed that economic intelligence has a positive but differential effect on the firm's performance. But some determinants of performance do not seem to take full advantage of the strategies of economic intelligence to which companies should attach greater importance.
\end{abstract}

Keywords: Economic intelligence; strategic watch; protection, influence; performance.

\section{Introduction}

Environmental changes and increased competition are making the environment increasingly unstable. Performance is therefore at the heart of the concerns of companies operating in the current context. The work of Choo (2001), emphasizes the importance of the openness of the company to its environment and its ability to acquire information useful for its operation, thus emphasizing the contribution of the day before. Other more recent studies (Elbashir et al., 2008) show that economic intelligence is likely to condition the performance of the company.

Certainly, economic intelligence represents for most managers an effective means of supporting these changes that affect the economy and a strategic tool capable of improving performance. However, it appears that Tunisian companies are not aware of this. Therefore, we will try to provide, at the end of this work, an answer to the following problem: What is the contribution of economic intelligence to the performance of Tunisian companies? To do this, we will start by defining the theoretical concepts and identifying the different variables that will appear in our research proposal at the end of which we will proceed to formulate the hypotheses. A field study will allow us to provide an answer to our problem.

\section{Literature review}

In what follows, we will present the theoretical framework and define our concepts based on a review of the literature that cannot be considered exhaustive. The notion of performance has long been considered vague and polysemous and has not known a generic definition. Some authors, including Hannan and Freeman (1977), have abandoned research in this area. Other authors have tried to explain the causes. Thus, some authors equate performance with the ability of the company to achieve objectives and perform tasks properly (Khemekhem, 1970). Others introduce the concepts of efficiency and effectiveness. Performance is then achieved if the company achieves the objective without wasting resources (Dubois and Jolibert, 1992; Georgopoulous and Tannenbaum, 1957). Dess and Robinson (1984) equate it with the ability of the company to move as far away from failure as possible and closer to success. In this same thread, is the approach of Seashore and Yuchtman (1967) who consider performance as the capacity of a firm to optimize the

\footnotetext{
* Corresponding author.

E-mail address: am.docteur@gmail.com (Amine Ben Hadj Hassine)
} 
allocation of resources to guarantee and optimize the operation of the company. These authors do not agree on the same definition of performance, but it can be concluded that performance resides in the ability of the company to allocate its resources in an efficient manner allowing it to achieve objectives and carry out its tasks properly, thus ensuring the proper functioning of the organization, its success and keeping it away from failure.

\subsection{Determinants of performance}

Even if the definitions of performance do not all converge, we can find authors who have focused their research on the determinants of performance. Thus, according to Dorner R. (2004) and in support of the work of many authors such as Lenz (1981) and Hansen and Wernerfelt (1989), the determinants of performance for a firm can be grouped into three categories which are broken down as follows:

a. Environmental determinants: The competitive game, as well as the strategies which result from it, and in particular the rules of competition, access to the market determined by the barriers to entry condition the performance of the company and reflect its ability to cope with multiple constraints imposed by the environment.

b. Organizational determinants: In the eyes of several authors such as Hansen and Wernerfelt (1989), Hofstede (1980), Rumelt (1982), and many others, a good number of organizational factors can influence the performance of a firm. Barbarel (1999) collects seven determinants:

-The organizational structure (Child, 1974; Williamson, 1975).

-The strategy of the company (Rumelt, 1974; Miles and Snow, 1978; Porter, 1980).

-The competitive position in its sector evaluated by its relative market share (Hansen and Wernerfelt, 1989).

-The size of the company (Rumelt, 1982); -The corporate culture (Hofstede, 1980).

-The history of the company (Hansen and Wernerfelt, 1989).

-The capital structure (Changanti and Damanpour, 1991).

c. Human determinants: In any performance appraisal process, the human factor is not without importance. Indeed, the quality of human resources and their motivation are indeed determining factors in the organization's quest for this performance.

\subsection{Economic intelligence}

In the literature, the concept has been approached from several points of view. We then find the authors who approach the subject with an emphasis on the collection, processing and dissemination of information (Lointier, 2000). Other authors emphasize the contribution of these practices to decision-making processes and describe them as a means of action allowing the anticipation and adaptation of the organization to its environment Simon (1976), Marmuse (1993), Jakobiak (1998), Bournois and Romani (2000), Martinet and Marti (2001). Other authors (Akgun et al., 2007) have emphasized the learning opportunities offered by business intelligence and intelligence processes through the collective interpretation of information. In this work, we will start from a functional approach to economic intelligence based on the definition of its functions and allowing to answer the question "what does it do? » In order to identify its impact on the determinants of performance.

\section{The functions of economic intelligence}

The intelligence function or strategic watch: This is the primary function of economic intelligence seen that it is its stimulus and the generator of information (Jakobiak, 1998; Baud, 1998). It results in the adoption of a vigil behavior. Within the framework of a normative approach, monitoring is considered to be a process that begins with the collection of information until it is disseminated within the organization. The work of Les (2003) and his team is part of this normative approach based on the monitoring process by proposing the VAS-IC (anticipative monitoringcollective intelligence) model. Strategic anticipatory watch (VAS), according to Lesca 1994, can be defined as being the voluntarist informational process by which the company listens in anticipation (or prospective) to early signals from its environment, socio-economic with the creative aim of opening up opportunities and reducing the risks associated with its uncertainty". 
However, in Tunisian companies, watch is not formalized and watch cells do not exist. This leads us to opt for an approach based on monitoring practices which therefore appears as a means allowing the company to collect information useful for its operation by having recourse to the information networks that companies weave with their environments, information and communication technologies and information systems allowing better information management (Jakobiak, 1998; Lesca, 1986; Besson and Laloum, 2003, Salles, 2003, Massé and Thibault, 2000).

Protect the achievements: The second function of economic intelligence is the protection function which consists in "protecting the company from the greed of the environment". Indeed, after having acquired the information essential to feed the decision-making process, it becomes essential to protect it (Villain, 1990, Besson and Laloum, 2003). Authors in the field of business intelligence and intelligence stress the importance of protecting all the company's intangible assets and its human resources. This intangible heritage includes the company's brand, its products and innovations, its image, and its reputation in the market. We then find patents, intellectual and industrial property, brand names, motivation, and training of staff by offering them opportunities for learning and teamwork (Besson and Laloum, 2003) and a good social climate, the various means of protecting information systems and company secrets, protecting access to the company.

Influence is to act so as not to suffer: Finally, economic intelligence consists of influencing the environment, acting to avoid its constraints and threats (Villain, 1990; Jakobiak, 1998; Besson and Laloum, 2003). Barbarel (1999) defines influence strategy as "the process which, at the initiative of an organism, aims to favorably modify its interactions with its environment". Fonvielle Networked companies will then voluntarily share information with the aim of preventing an event that could constitute a threat for the company from recurring, to validate a decision and cushion the shock of crises (Besson and Laloum, 2003). These influencing strategies can then take the form of simple marketing and environmental communication strategies aimed at improving the image and reputation of the company as they can extend to more important practices and resulting in the lobbying and government influence. Therefore, the objectives sought by lobbying. They are manifested in the desire of companies to avoid regulatory constraints that do not serve their interests, as well as in an offensive aspect which consists in acting in a way that changes the rules of the game. Finally, a third motivation is that of seeking financial interests (Clamen, 2005) cited by Besson and Laloum (2003).

\subsection{Links between economic intelligence and performance}

Our job is to find intersections between business intelligence, which will manifest itself through the following functions: intelligence function (watch), protection function, and influence function. On the other hand, the determinants of performance are as follows: Our research proposal is formulated as follows:

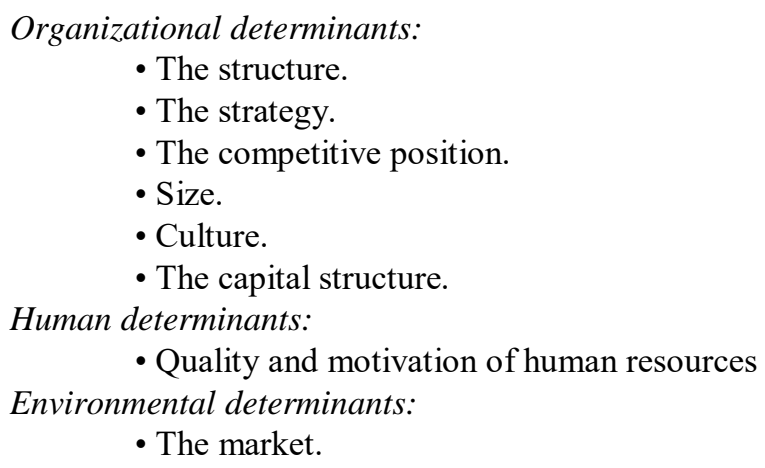

\section{a. Intelligence function and determinants of performance}

The company's openness to its environment has an influence on the following different variables:

The structure: (March, 1963; Lawrence and Lorsch, 1973, Aguilar, 1967). The company's openness to its environment allows the company to increase its ability to adapt and therefore improve its flexibility of the company will then seek to restructure itself according to the requirements of its environment. The formalization of procedures, the 
effectiveness of the management style and therefore the degree of centralization depend on the openness of the company to its environment. In fact, in stable environments, a high degree of formalization can guarantee performance. However, in unstable environments, formalization can act as a brake on change and adaptation by causing structures to emerge that are too slow and unable to keep up with the changing environment, leading to real organizational rigidity. The degree of formalization is often linked to the specialization of tasks which results in extreme fragmentation.

The strategy: openness of the company to its environment allows the company to reduce uncertainty and improve decision-making (Pateyron, 1994) as it allows it to avoid strategic surprises as described by Pateyron (1994). The collection of information then allows the company to base its decision-making process and support the design of the strategy.

The competitive position: the day before allows it to acquire information on the competition it could then formulate the strategies necessary to overcome it, as it allows it to improve its capacity for innovation (Jakobiak, 1991; Julien and Lachance, 2001) and consequently its position on the market.

Culture: corporate culture is the set of rules and values shared by individuals in the same organization, capable of helping the company to cope with problems of external adaptation and internal integration (Schein, 1986). This culture depends on how open the company is to its environment.

Quality of human resources and motivation: the more open the company is to its environment, the more its members will be likely to adopt a state of mind likely to improve its performance (Lesca, 2003).

The market: the impact of the day before on the functioning of the market is reflected in its action on its transparency. Opening the business to its environment would help increase the asymmetry of information to the benefit of the business that owns it.

The information systems would exert an influence on the following variables:

- The structure: information systems would have an impact on the structure by acting on the division of labor. Indeed, they offer opportunities for information sharing, thus strengthening teamwork (Bellier et al., 2000) and promoting the formalization of procedures. According to Shang and Sedon (2000), companies seek to increase their productivity, profitability and in particular their efficiency which will allow them to overcome local barriers, companies are then led to redistribute decision-making power through systems of information. Indeed, they promote decentralization in favor of those who are closer to the field.

- The strategy: information systems support the information process from the search for information to its dissemination to the stakeholders concerned. These information systems would thus contribute to the formulation of the strategy.

- Size: The review of the literature allows us to conclude that the technology influences height.

- Culture: information systems are likely to disrupt uses, work methods and relationships between individuals. A culture that promotes the use of these should accompany the implementation of information systems. The impact can be positive, as it could be negative.

- The quality of human resources: studies8 have shown that the introduction of information systems in the organization leads to the training of personnel in the use of technologies, thus contributing to the improvement of the quality of human resources, like this contributes to the recruitment of qualified personnel.

- The market: information systems promote the birth of networks of companies that will act together on the functioning of the market where a company or a network of companies could benefit from a monopoly situation. They would act on market access by putting up barriers to entry.

These remarks lead us to formulate our first hypothesis as follows:

\section{H1: Monitoring positively influences the determinants of performance.}

\section{b. The protection function and determinants of performance:}

The protection function acts mainly on the following variables: 
- The structure: It acts on formalization by helping to formalize the management of information and information in order to protect it. With protection comes the centralization of information to protect secrets. Protecting human resources by motivating them through teamwork would contribute to a reorganization of work.

- The strategy: the protection of resources and intangible heritage allows the company to fully benefit from them for the design of the strategy.

- Competitive position: protecting the assets, innovations, brand name and information allows the company to stay ahead of its competitors and to benefit from a better position in the market.

- Size: the protection of the assets of the company would contribute to the increase of innovations which would offer new outlets to the company and would result in an increase in turnover.

- Culture: the protection of innovations through the filing of patents, intellectual and industrial property promote the establishment of a culture of innovation and excellence.

- The capital structure: protecting the assets of the company can be a good argument for attracting partners, or triggering state aid, resulting in a change in the capital structure.

- The quality of human resources: The protection function allows the company to protect its human resources by offering them training sessions, learning opportunities and good remuneration, which would contribute to their motivation and the improvement of their skills.

- The market: By protecting innovations by filing patents, the company can have a monopoly on a specific product for a specified period. The protection function thus acts on the functioning of the market.

Likewise, patenting can create barriers to entry and serve to limit imitations. Hence our second hypothesis:

\section{H2: The protection function positively influences the determinants of performance.}

\section{c. The influence function and determinants of performance}

This function has an impact on the following variables:

- The structure: in lobbying and influencing strategies, companies use partnerships to increase their power of influence. Strategies of partnerships and alliances push companies to restructure, which leads them to review the division of labor, formalization and centralization of decision-making power.

- Strategy: influencing strategies lead companies to align their strategies according to the strategic choices they make.

- Competitive position: marketing and environmental communication strategies help to improve the image of the company and therefore its sales and market share, hence improving its competitive position.

- Size: Influence strategies can be carried out individually or in partnership, hence increasing their size.

- Culture: within the framework of partnership strategies, companies will tend to adapt their culture. Also, culture could be influenced by the success of certain marketing and environmental communication strategies, or even lobbying.

- The capital structure: lobbying, likely to influence the public authorities, would allow the company to benefit from subsidies and state aid, thus affecting the capital structure.

- The quality of human resources: State aid can be in the form of providing training opportunities for company staff, thereby improving the quality of human resources.

- The market: the marketing communication strategies are likely to increase the differentiation at the level of the product thus acting on the functioning of the market. Likewise, partnership lobbying is likely to erect barriers to entry, directly affecting market access.

Our third hypothesis will then be formulated as follows:

H3: The influence function acts positively on the determinants of performance, certainly, economic intelligence represents for most managers an effective means of supporting these changes that affect the economy and a strategic tool capable of improving performance.

However, it appears that Tunisian companies are not aware of this. Therefore, we will try to provide, at the end of this work, an answer to the following problem: What is the contribution of economic intelligence to the performance of Tunisian companies? To do this, we will start by defining the theoretical concepts and identifying the different 
variables that will appear in our research proposal at the end of which we will proceed to formulate the hypotheses. A field study will allow us to provide an answer to our problem.

\section{Research methodology}

The chosen sampling method is the reasoned choice which will not offer the possibility of a statistical inference but will allow an analytical inference and therefore "to generalize theoretical propositions on the basis of a logical reasoning". The choice of the sampling method is explained by the fact that the database available on the API website does not provide information on economic intelligence practices. In addition, the Tunisian industrial fabric is made up of 5,839 companies, including 3,052 that are not fully exporting, which makes it very difficult to build a new sampling frame. The choice of the manufacturing industries sector is explained by the fact that the manufacturing industry has an important place in the Tunisian economy, thanks to the increase of its production (14\%) and of the added value (6\%). The most important thing is that this sector is a very competitive sector, its share in the GDP is significant (35.4\%) and investments in the sector show an increase of 15\% between 2014 and 2018. Furthermore, it should be noted that this sector is the most subject to the phenomena of globalization, especially after the implementation of the free trade agreement with the European Union. Finally, we should point out that we received feedback from 140 questionnaires. We kept only the questionnaires whose companies claim to have or display competitive intelligence practices as we eliminated the incomplete questionnaires which brought us to a total of 92 usable questionnaires.

\subsection{Measurement of variables}

In order to operationalize the determinants of performance, we use predefined measurement scales. Other variables (culture, market) were operationalized using the social science concept measurement approach of Lazersfeld (1967). Finally, to generate the items relating to economic intelligence, we use the paradigm of Churchill (1979). We then carried out five semi-structured qualitative interviews thus following the principle of literal replication. It is estimated that the replications of these cases would be likely to convince on the themes studied. The rating scales are 5 points scales.

\subsection{Statistical tests}

The reliability and validity tests as well as the principal component analyze allowed us initially to purify our measurements and to train our factors for the realization of the multiple regressions which allowed us to test our hypotheses. This regression "is an extension of simple regression where the dependent variable is regressed on a set of variables. This multivariate technique is the most used to predict and explain."

\section{Research methodology}

Reading the table 1, we can conclude that the organizational structure seems rather dependent on the influence function. The protection function seems to have no effect on the organizational structure and the watch only influences the formalization of procedures since the watch is mainly based on the formalization of information management. Thus, Tunisian companies seem to remain faithful to pyramidal and archaic structures. The day before, based on information systems does not seem to influence the organizational structure at the level of the division of labor and the distribution of power: The establishment of advanced and efficient information systems requires a period of adaptation whereby the organizational structure will take advantage of the information advantage. Tunisian companies seem to prefer to keep control by opting for structures that tend towards the centralization and fragmentation of tasks (Psychosociological approach to organizations Eugène, 1983; 1991; 1993). Size is the only variable that is not influenced by any of the business intelligence functions. This result cannot be generalized and remains limited to our sample.

The design of the strategy seems to take advantage of the informational advantage offered by the functions of 
economic intelligence thus improving their competitive position. However, the size of the company appears to be unaffected. Tunisian companies, mainly SMEs, prefer to keep their average size since its increase would generate additional organizational costs, act on the distribution of power (Bienaymé, 1971), and would influence the motivation of the staff and their contribution to the achievement objectives (Larcon and Reiter, 1979). Protection and monitoring both act on the corporate culture. The first would help protect culture by fostering cohesion between members and strengthening shared values such as involvement, excellence, professionalism, and innovation. However, the day before acts negatively on the culture: the opening of the company to its environment can be accompanied by a refusal of certain environmental changes (economic and social) or the refusal of new rules or values (change of certain practices, organizational innovations).

Monitoring has no impact on human resources and the market depends only on the influence function. These results are specific to our sample and cannot be generalized.

In this research we were interested in the role that economic intelligence strategies can play in the conditioning of performance. Our results show that economic intelligence has differential effects on the determinants of performance selected (see table 4).

Influencing strategies have the most effect on the determinants of performance, thus emphasizing the contribution of offensive behavior. The company seems to take advantage of its strengths in order to influence its environment and shape it as it sees fit, in a way that promotes the achievement of its strategic goals. As part of their influence strategies, $60 \%$ of Tunisian companies still use marketing communication strategies, 50\% often engage in sponsorship and patronage actions.

However, Tunisian business leaders show a certain mistrust when the subject of lobbying is brought up and emphasize compliance with competition law and their aversion to anti-competitive practices. This does not prevent them from serving their interests by having recourse to the UTICA (72\% often) and business associations (always 10\%), to obtain state aid and subsidies (60\% often) and influence the public authorities (40\% often). As for protection, some aspects are neglected. Protection actions relate more to information, information systems and human resources. Less emphasis is placed on protecting innovations (20\% still file patents). Therefore, the protection function has no effect on the market. Finally, by observing the statistics relating to watch practices within Tunisian companies, we can say that it is not taking all its importance in a sector where competition is increasingly fierce. Companies do not have watch units and the activity remains informal. The companies surveyed state that they often (40\%) use the Internet, customers (50\% always), personal networks (40\% always and $40 \%$ often), partners (30\% always). $30 \%$ of companies say they always use databases, $10 \%$ always use specialized institutes and $12 \%$ say they often exchange information with competitors during meetings of company managers. Tunisian companies seem to prefer not to invest too much in collecting information if they can acquire it for free. As for the use of information systems, $60 \%$ of companies say they still use software specialized in information management. However, these companies appear not to take full advantage of the competitive advantage inherent in their use.

These results allow us to conclude that the functions of economic intelligence are not being properly exploited. Tunisian companies are not yet aware of the contributions of the practice. Work like that of Kammoun (2007-2009) is part of a research aiming to convince Tunisian companies of the usefulness of the day before and lead to the establishment of a process of attention to the environment. Other works such as that of Tamboura and Ben Ammar (2009), emphasize the importance of monitoring and direct their research towards the identification and validation of critical success factors for the establishment of a strategic watch system. Among these factors are mainly the need to formalize the monitoring process and the implementation of efficient information systems associated with their proper use. Factors that are lacking in Tunisian companies. 
Ben Hadj Hassine | Quantitative Economics and Management Studies (QEMS), 2021, 2(4): 233-243

Table 1. Effects of economic intelligence functions on the determinants of performance (structure)

\begin{tabular}{|c|c|c|c|c|c|c|}
\hline & \multicolumn{2}{|c|}{$\begin{array}{l}\text { Regression } 1 \\
\text { VD=PARCEL }\end{array}$} & \multicolumn{2}{|c|}{$\begin{array}{l}\text { Regression } 2 \\
\text { VD=FORM }\end{array}$} & \multicolumn{2}{|c|}{$\begin{array}{c}\text { Regression } 3 \\
\text { VD=Cent }\end{array}$} \\
\hline & $T$-STAT & Prob. & $T$-STAT & Prob. & $T-S T A T$ & Prob. \\
\hline Const. & $\begin{array}{c}0,000 \\
(-3,036 \mathrm{E}-16)\end{array}$ & 1,000 & $\begin{array}{c}, 000 \\
(-6,220 \mathrm{E}-16)\end{array}$ & 1,000 & $\begin{array}{c}0,000 \\
(-1,666 \mathrm{E}-16)\end{array}$ & 1,000 \\
\hline Veille & $\begin{array}{c}0,522 \\
(0,109)\end{array}$ & 0,603 & $\begin{array}{l}1,720 \\
(, 272)\end{array}$ & 0,089 & $\begin{array}{c}-0,873 \\
(-0,080)\end{array}$ & 0,385 \\
\hline Protection & $\begin{array}{c}-1,373 \\
(-0,255)\end{array}$ & 0,173 & $\begin{array}{c}-0,439 \\
(-0,062)\end{array}$ & 0,662 & $\begin{array}{c}-0,580 \\
(-0,047)\end{array}$ & 0,563 \\
\hline Influence & $\begin{array}{c}6,381 \\
(1,077)\end{array}$ & 0,000 & $\begin{array}{l}5,899 \\
(, 758)\end{array}$ & 0,000 & $\begin{array}{l}15,032 \\
(1,111)\end{array}$ & 0,000 \\
\hline $\mathrm{R} 2$ & \multicolumn{2}{|c|}{0,880} & \multicolumn{2}{|c|}{0,930} & \multicolumn{2}{|c|}{0,977} \\
\hline F stat. & \multicolumn{2}{|c|}{$214,905(, 000)$} & \multicolumn{2}{|c|}{$392,496(0,000)$} & \multicolumn{2}{|c|}{$1244,931(0,000)$} \\
\hline
\end{tabular}

Table 2. Effects of economic intelligence functions on the determinants of performance (continued)

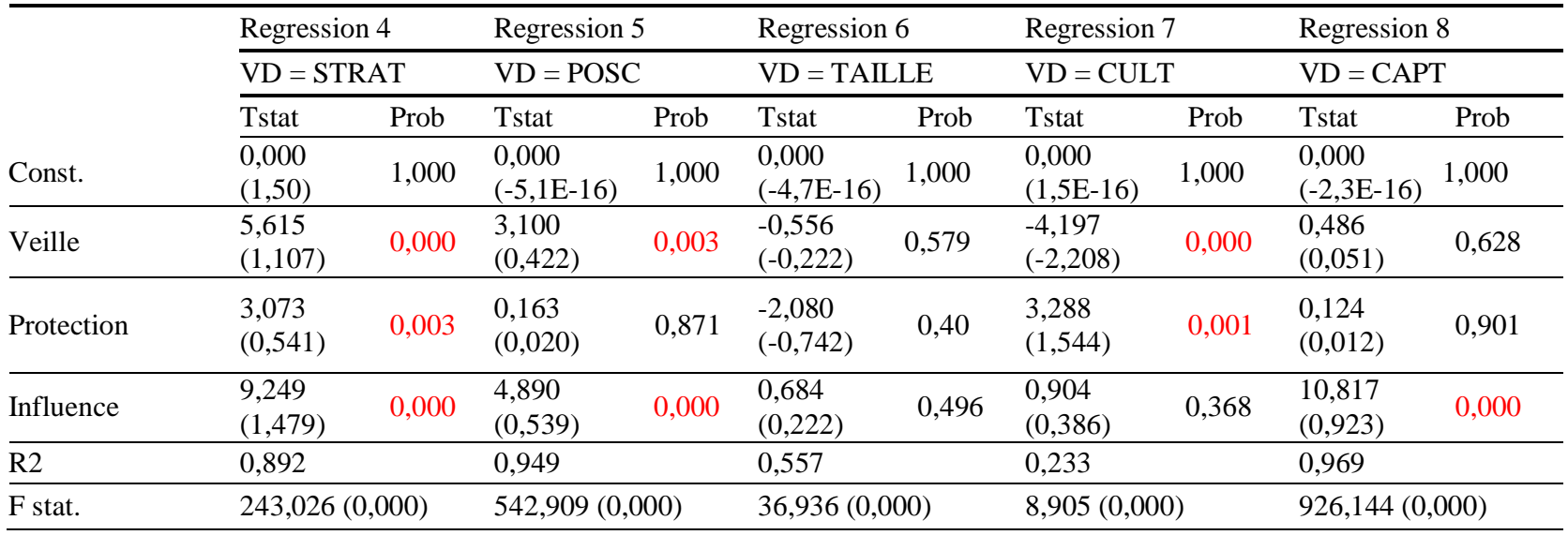

Table 3. Effects of economic intelligence functions on the determinants of performance (continued)

\begin{tabular}{|c|c|c|c|c|}
\hline & \multicolumn{2}{|c|}{$\begin{array}{c}\text { Regression } 9 \\
\text { VD=RH }\end{array}$} & \multicolumn{2}{|c|}{$\begin{array}{l}\text { Regression } 10 \\
\text { VD=MARCHE }\end{array}$} \\
\hline & T STAT & Proba & T STAT & Proba \\
\hline Const. & $\begin{array}{c}0,000 \\
(-4,311 \mathrm{E}-16)\end{array}$ & 1,000 & $\begin{array}{c}0,000 \\
(-8,863 \mathrm{E}-17)\end{array}$ & 1,000 \\
\hline Veille & $\begin{array}{c}-1,459 \\
(-0,367)\end{array}$ & 0,148 & $\begin{array}{c}0,013 \\
(0,003)\end{array}$ & 0,989 \\
\hline Protection & $\begin{array}{c}5,291 \\
(1,186)\end{array}$ & 0,000 & $\begin{array}{c}1,375 \\
(0,234)\end{array}$ & 0,173 \\
\hline Influence & $\begin{array}{c}0,397 \\
(0,081) \\
\end{array}$ & 0,692 & $\begin{array}{c}4,655 \\
(0,718)\end{array}$ & 0,000 \\
\hline $\mathrm{R} 2$ & \multicolumn{2}{|c|}{0,825} & \multicolumn{2}{|c|}{$0, \overline{900}$} \\
\hline F stat. & \multicolumn{2}{|c|}{$138,405(0,000)$} & \multicolumn{2}{|c|}{$262,969(0,000)$} \\
\hline
\end{tabular}


Ben Hadj Hassine | Quantitative Economics and Management Studies (QEMS), 2021, 2(4): 233-243

Table 4. Summary of results: total effect of economic intelligence on the determinants of performance

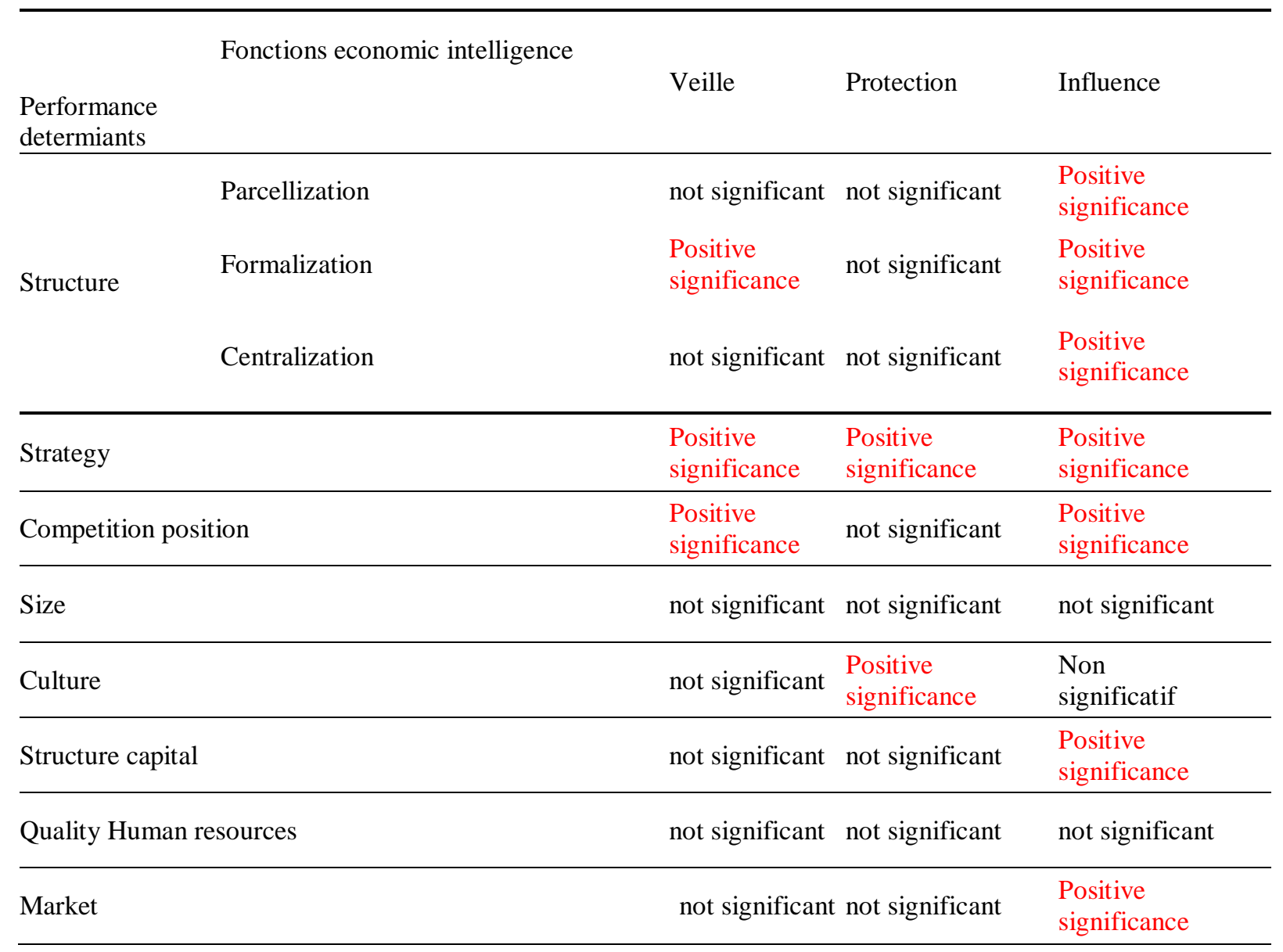

Table 5. Validation of hypotheses

\begin{tabular}{ll}
\hline \multicolumn{1}{c}{ Hypothesis } & Validation \\
\hline $\begin{array}{l}\text { H1: veille influence positively the } \\
\text { determinants performance. }\end{array}$ & Partially validated \\
$\begin{array}{l}\text { H2: fonction protection influence } \\
\text { positively the determinants performance. }\end{array}$ & Partially validated \\
$\begin{array}{l}\text { H3: fonction influence have positively } \\
\text { determinants performance. }\end{array}$ & Partially validated \\
\hline
\end{tabular}

\section{Conclusion}

By way of conclusion, we believe that we have provided an answer to our problem which was formulated as follows: What is the contribution of economic intelligence to the performance of Tunisian companies? The results of our empirical research allowed us to conclude that the functions of economic intelligence contribute differently to the improvement of performance and have contributed in different proportions to the conditioning of the latter. We consider that we have clarified the theoretical concepts studied as we believe we are convinced of the usefulness and 
importance of economic intelligence strategies and of encouraging Tunisian companies to integrate these practices into their information habits in their giving more importance. However, our research work does not escape certain limitations. Indeed, the answers processed are all perceptions of the managers, the assessments are therefore subjective. Likewise, the limited size of our sample and the sampling method used do not allow us to generalize our results.

\section{References}

Aguilar, F. (1967). Scanning the business environment, Macmillan, New York.

Akgun, A.E., Byrne, J.C., Lynn, G.S., \& Keskin, H. (2007). Organizational unlearning as changes in beliefs and routines in organizations, Journal of organizational change management, 20(6), 798-812. https://doi.org/10.1108/09534810710831028

Baud, J. (1998). Encyclopédie du renseignement et des services secrets, Lavauzelle, Paris.

Besson M. et Laloum Y. (2003). Tout savoir sur vos partenaires: Le guide du renseignement commercial, Editions d'Organisation.

Bienaymé, A. (1971). La croissance des entreprises, T1. Analyse dynamique des fonctions de la firme, Bordas, Paris.

Bournois, F., \& Romani, P.J. (2000). L’intelligence économique et stratégique dans les entreprises françaises, Economica, Paris.

Child, J. (1974). Managerial and organizational factors associated with company performance, Journal of Management Studies, 11(3), 175-198. https://doi.org/10.1111/j.1467-6486.1974.tb00693.x.

Choo, W.C. (2001). Environmental scanning as information seeking and organizational learning, Information Research, 7(1), 25-36. http://informationr.net/ir/7-1/paper112.html.

Churchill, G. (1979). A paradigm for developping better mesures of marketing constructs, Journal of Marketing Research, 26(1), 64-73. https://doi.org/10.1177\%2F002224377901600110.

Clamen, M. (2005). Manuel de Lobbying, Dunod, Paris.

Dess, G.G., \& Robinson, R.B. (1984). Measuring Performance in the absence of objective measures: the case of privately held firm Conglomerate Business unit, Strategic Management Journal, 5(3), 265-273. https://doi.org/10.1002/smj.4250050306

Dorner, R. (2004). Les représentations de la performance au sein 'un même secteur : le cas des dirigeants de voyagistes, Cahiers de recherche du CREPA, Univ. Paris Dauphine, article présenté lors de la 13ème conférence de l'AIMS, Normandie, 1-3.

Dubois, P.L., \& Jolibert, A. (1992). Le marketing: Fondements et pratiques, Economica, Paris.

Elbashir, M.Z., Collier, P.A., Davern, M.J. (2008). Measuring the effects of business intelligence systems: the relationship between business process and organizational performance, International journal of accounting systems, 9(3), 135-153. https://doi.org/10.1016/j.accinf.2008.03.001.

Hannan, M.T., \& Freeman, J.H. (1977). The population ecology of organizations, American Journal of sociology, 82(5), 929-964. https://www.jstor.org/stable/2777807.

Hansen, G.S., \& Wernerfelt, B. (1989). Determinants of Firm Performance: The Relative Importance of Economic and Organizational Factors, Strategic Management Journal, 10(5), 399-411. https://doi.org/10.1002/smj.4250100502.

Hofstede, G. H. (1980). Cultures and Organizations, Mc-Graw Hill.

Jakobiak, F.(1998). Pratiques de la veille technologique, Les éditions d'organisation, Paris. 
Julien, P.A., \& Lachance, R. (2001). Dynamic regions and high-growth SMEs: uncertainty, potential information and weak signal networks, Human Systems Management, 20(2), 237-248. https://content.iospress.com/articles/human-systems-management/hsm483

Kammoun, C.S. (2009). Comment convaincre de l'utilité de la veille stratégique ? Le cas d'une PMI tunisienne, Revue des sciences de gestion : Direction et gestion, 3-4(237-238), 195-205. https://doi.org/10.3917/rsg.237.0195.

Khemekhem, A. (1970). La dynamique du contrôle de gestion, Bordas, Paris.

Larcon, J.P., \& Reiter, R. (1979). Structure de pouvoir et identité de l'entreprise, Nathan, Paris.

Lawrence, P.R, \& Lorsch, J.W. (1973). Adapter les structures de l'entreprise, intégration ou différentiation, Editions d'organisation, Paris.

Lazersfeld, P. (1967). Des concepts aux indices empiriques, In Boudon R. et Lazersfeld P. Editions Le vocabulaire des Sciences Sociales, Paris.

Lenz, R.T. (1981). Determinants of organizational performance: An interdisciplinary review, Strategic management journal, 2(2), 131-154. https://doi.org/10.1002/smj.4250020204.

Lesca, H. (1982). Structure et système d'information facteurs de compétitivité de l'entreprise, Masson, Paris.

Lesca, H. (2003). Veille stratégique : La méthode L.E. SCAnning, Editions EMS, Management et société.

Lointier, P. (2000). Les limites de l'intelligence économique: Commentaires de P. Lointier, Revue de l'association des diplômés de l'IAE, 162, 15-20. https://www.strategie-aims.com/events/conferences/13-xeme-conference-de1-aims/communications/2383-intelligence-economique-acception-francaise-etmultidimensionnalite/download

Marmuse, C. (1993). Le diagnostic stratégique : une démarche de construction de sens, Finance Contrôle Stratégie, 2(4), 77-104. https://www.strategie-aims.com/events/conferences/15-viiieme-conference-de-laims/communications/2327-le-diagnostic-strategique-une-demarche-de-construction-de-sens/download.

Martinet, B., \& Marti, Y.M. (2001). Intelligence économique, comment donner de la valeur concurrentielle à l'information, Editions d'organisations, Paris.

Maryse, S. (2006). Stratégie des PME et intelligence économique, une méthode d'analyse du besoin, Economica, Paris.

Massé, G., \& Thibaut, F. (2000). Intelligence économique : Un guide pour une économie de l'intelligence, De Boek Université, Bruxelles.

Pateyron, E.A. (1994). Le management stratégique de l'information, Economica, Paris.

Rumelt, R. P. (1982). Diversification strategy and Profitability, Strategic Management Journal, 3(4),359-369. https://doi.org/10.1002/smj.4250030407

Rumelt, R.P. (1974). Strategy, structure and economic performance, Cambridge MA: Harvard University Press.

Schein, E.H. (1986). Organizational culture and leadership, Jossey-Bass, San Francisco.

Seashore, B.S., \& Yuchtman, E. (1967). Factorial analysis of organizational performance, Administrative science quarterly, 3 (3), 377-395. https://doi.org/10.2307/2391311.

Simon, H.A. (1976). From substantive to procedural rationality: Method and appraisal in economics, Cambridge, Cambridge University Press, pp.129-148.

Villain, J. (1990). L'entreprise aux aguets, Paris, Masson.

Williamson, O. (1975). Markets and hierarchies, New York, The Free Press. 